\title{
FREQUENCY OF FETO-MATERNAL COMPLICATIONS AND MORTALITY IN GRAND MULTI PARA WOMEN
}

\section{SAIQA NOOR}

1. Department of Obstetrics and Gynecology, DHQ Hospital, Timergara.

\section{ABSTRACT}

BACKGROUND: Grand multipara is the woman, who has given birth to five or more viable infants. Grand multiparity (GMP) in relation to obstetric performance is labeled as high risk: a pregnancy in which there is a factor maternal or fetal that will adversely affect the outcome of pregnancy.

OBJECTIVE: To observe the frequency of different maternal and fetal complications associated with grand multiparity

METHODOLOGY: A prospective, descriptive type of study conducted at Gynae 'A' Unit, Postgraduate Medical Institute, Lady Reading Hospital Peshawar from January 2008 to December 2008. All admitted antenatal patients who had five or more viable pregnancies were included in the study. All possible maternal and fetal complications were looked for and complete examinations of the neonates were done in liaison with pediatrics unit.

RESULTS: Amongst the hundred GMP women, 58\% of the women had parity of 5 to $7,37 \%$ had 8 to 10 children while $5 \%$ had more than 10 viable pregnancies. Total $56 \%$ patients had normal vaginal deliveries while 17 patients had C-section. Anemia, hypertension, diabetes, mal-presentation and antepartum hemorrhage were common prenatal complications.

Prolonged and obstructed labour $8 \%$, postpartum haemorrhage $8 \%$, precipitate labour $5 \%$, cord prolapse $2 \%$, ruptured uterus $2 \%$, shoulder dystocia $1 \%$ and retained placenta $1 \%$, were different complications. The major fetal complications seen were macrosomia, birth injuries, frequent neonatal ICU admissions, major congenital abnormalities and perinatal deaths. Total perinatal deaths were $07 \%$, total maternal mortality was $03 \%$, two women died due to severe haemorrhage while one died due to eclampsia.

CONCLUSION: There is still high frequency of grand multiparity in our population which is associated with frequent maternal and fetal complications. This leads to high maternal and fetal mortality.

KEY WORDS: Grand Multiparity, Maternal complications, Fetal Complications, Maternal Mortality, Fetal Mortality.

\section{INTRODUCTION}

Parity refers to the number of times a woman has given birth to an infant, dead or alive after the age of viability ${ }^{1}$. Grand multipara is the woman, who has given birth to five or more viable infants $^{2}$. Grand multiparity (GMP) in relation to obstetric performance is labeled as high risk. A high risk pregnancy is any pregnancy in which there is a factor maternal or fetal that will adversely affect the outcome of pregnancy.

It is believed that increasing parity after the fifth delivery increases the maternal or perinatal morbidity and mortality. In terms of minimal risk concept the safest babies to have are second, third and fourth. The hazards are greater for women in their fifth pregnancy and onwards ${ }^{2}$.

Pregnancy after fifth delivery is viewed with anxiety, especially by obstetricians in developing countries working with inadequate facilities. High parity is still common with serious consequences to the fetus, the mother, the family and society ${ }^{3}$.

Solomon had rightly pointed out in 1934 that in child bearing, 'practice does not make perfect'. The incidence of grand multiparity has decreased in most Western Countries in recent years. There is tendency to disregard grand multiparity in modern western literature. Most of the textbooks 
contain no account of this subject. This has resulted in insufficient data on outcome of grand multiparity in this era of modern obstetrics. In most of the western countries, the grand multiparity is not so common. Most of their studies have concluded that grand multiparity should not be regarded as an obstetric risk in the presence of satisfactory health care ${ }^{4,5,6}$.

In the underdeveloped countries, grand multiparity is still common with its attendant maternal and fetal complications ${ }^{1,3,7}$.

Large family size is not uncommon in Pakistan with tendency towards multiparity. Pakistan is the 6th most populous nation in the world after China, India and Indonesia etc. The population of Pakistan is about 185 millions with birth rate of $36 / 1000$, fertility rate of $2.6 \%$ and maternal mortality rate of $350 / 100,000$ live births. Although the prevalence of grand-multiparity is on the downward trend, it still remained an obstetric risk, therefore, the importance of booking and delivery in a well equipped facility should be emphasized among the obstetric population so as to reduce the complications that were found to be associated with the condition ${ }^{8}$.

Large family size is highly prevalent in Pakistan due to cultural, religious and social reasons. Due to poor access to health care facilities, both the maternal and fetal complications associated with grand multiparity are high in this part of the world. Lack of education, the interventions by TBA's and late referral to the specialist centres further aggravates the problem.

\section{METHODOLOGY}

This prospective study which included 100 cases of grand multiparous women was carried out in Gynae "A" Unit, Postgraduate Medical Institute, Government Lady Reading Hospital, Peshawar from January 2008 to December 2008. The P.G.M.I., Lady Reading Hospital, Peshawar is one of the busiest and largest tertiary care hospital which has a wide catchment area including suburbs of Peshawar and receives patients from whole of Khyber Pukhtunkhwa and some parts of Afghanistan.

All antenatal patients admitted in Gynae "A" Unit, LRH, Peshawar, who had five or more viable pregnancies were included in the study. A detailed history was taken and relevant data was collected on a proforma. All possible maternal and fetal complications were looked for and complete examination of the neonates were done in liaison with Paediatric unit.

All antenatal consecutively admitted patients in Gynae "A" Unit of PGMI, Lady Reading Hospital, Peshawar, who had five or more viable pregnancies were included in the study. All women with less than five viable pregnancies were excluded from the study. Abortion, ectopic pregnancies and hydatiform mole were not regarded as pregnancy. Multiple pregnancies were regarded as single pregnancy. Data was analyzed using SPSS version 14 .

\section{RESULTS}

Amongst the hundred GMP women, 58\% of the women had parity of 5 to $7,37 \%$ had 8 to 10 children while $5 \%$ had more than 10 viable pregnancies. Seventeen patients had C-section for different indications; like CPD 3\%, Foetal distress 3\%, Emergency repeat C-Section 2\%, Placenta previa $2 \%$, Transverse lie $2 \%$, Elective repeat $\mathrm{C}$-section $1 \%$, PET $1 \%$, and $1 \%$ each for cord prolapse and face presentation. Anemia, hypertension, diabetes, mal-presentation and antepartum hemorrhage were common prenatal complications (Table 1).

Table No 1

\begin{tabular}{|l|c|}
\hline \multicolumn{2}{|c|}{ PRENATAL COMPLICATIONS } \\
\hline Complication & $\begin{array}{l}\text { No. of } \\
\text { Cases }\end{array}$ \\
\hline Anemia & 30 \\
\hline Malpresentation & 09 \\
\hline APH & 07 \\
\hline Diabetes Mellitus & 06 \\
\hline PIH & 06 \\
\hline Hypertension (known) & 05 \\
\hline Twins & 04 \\
\hline
\end{tabular}


Labour and postpartum complications were $43 \%$ of total patients (Table 02).

TABLE No 2

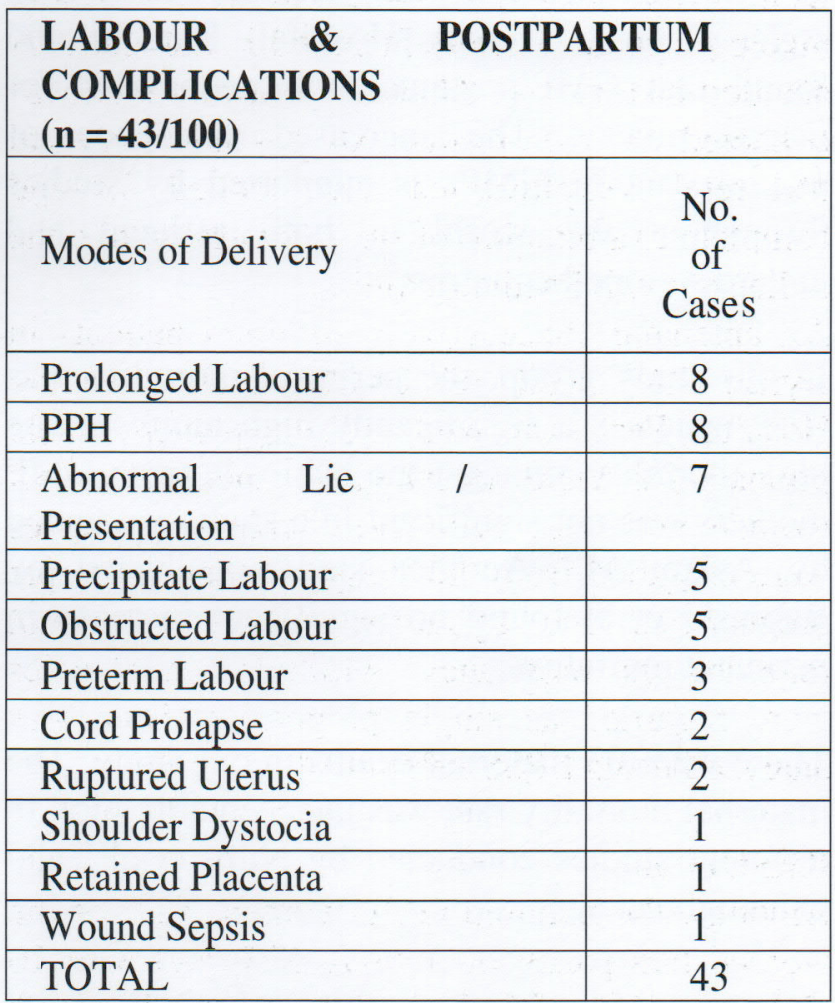

The major fetal complications seen were $58 \%$ among them macrosomia $23 \%$, birth injuries $12 \%$, frequent neonatal ICU admissions $6 \%$, major congenital abnormalities $5 \%$, perinatal deaths $7 \%$ and low birth weight were 5\% Total perinatal deaths were $07 \%$. The major causes of perinatal mortality were congenital anomalies $3 \%$, prematurity $1 \%$, obstruced labour $1 \%$, birth asphyxia $1 \%$, and septicemia $1 \%$. . Total maternal mortality was $03 \%$, two women died due to severe haemorrhage while one died due to eclampsia.

\section{DISCUSSION}

High parity with its attendant complications is still common in developing countries ${ }^{9}$. It is difficult to ascertain the effect exerted on pregnancy outcome by grand multiparity alone as this condition is invariably associated with advanced maternal age and low socioeconomic status. Both these variables can adversely affect the outcome of pregnancy. In grand multipara, belonging to low socioeconomic class, medical problems usually coexist.

Our study has confirmed the findings of the studies conducted in other parts of this country, most of which are consistent with increased incidence of complications associated with grand multiparity $^{3,9,10}$.

Babinski et al did match for age and socioeconomic status. They found that high parity groups have their own risk factors, but the rate of some complications decrease with high parity. Our study is in contrast to the studies conducted in Western World and adds weight to the local studies ${ }^{1,9,10,11}$ regarding the incidence of different complications.

Due to narrow spacing of pregnancies the women were unable to replenish their iron stores and their $\mathrm{Hb}$ drops with repeated pregnancies and blood loss. This finding is consistent with the study done by Munim et $\mathrm{al}^{9}$, at Agha Khan University Hospital, Karachi and Malik et al at Services Hospital, Lahore and also with studies from other parts of the world ${ }^{11}$.

The hypertension and diabetes was a common occurrence in our study. The association of diabetes and hypertension with grand multiparity has been described by different studies throughout the world ${ }^{3,5,9,12}$ Some of which relate this high incidence with increasing age of the mother. The finding of higher rate of APH in our study is consistent with the local studies, ${ }^{1,10}$ and studies from other underdeveloped countries ${ }^{3}$.

There were total 07 cases of APH amongst 100 grand multiparous women. The major contribution was abruptioplacenta and placenta previa. The increased incidence of abruptioplacenta and placenta previa amongst GMP's has been reported by different national and international studies ${ }^{4,10,13,14}$. In contrast no significant difference was found in the incidence 
of placenta previa, abruptioplacenta and undetermined causes of APH by Aslam M $^{1}$.

Due to increase in lordosis of lumber spine and pendulous abdomen in GMP's, they are said to have increased risk of abnormal presentation of fetus. In our study $84 \%$ fetuses were cephalic at presentation while $16 \%$ had abnormal presentation the common amongst which were breech and transverse lie.Malpresentation was found to be significantly increased (6.2\%) amongst grand multiparas in the study conducted by Maymon et $\mathrm{al}^{15}$.

The rate of both instrumental deliveries and caesarean section were high in our study, 17 caesarean sections were performed in 100 cases of GMPs. Our study results are supported by some local studies 9 while others found no significant increase in C-sections amongst GMPs ${ }^{1}$.

The rate of $\mathrm{C}$-section was found to be significantly increased in the study conducted by Odukogbe et $\mathrm{al}^{3}$ at Nigeria where it was $24 \%$ and $09 \%$ in two different groups of GMP's. The rate of $\mathrm{C}$-section has also been reported to be increased in different studies conducted in western world with sufficient antenatal care ${ }^{4}$. Sipila et al in a study in Finland found decreased incidence of C-section amongst GMP's ${ }^{16}$.

Eight (08) patients in our study group suffered with severe postpartum haemorrhage. Amongst them 02 patients had ruptured uterus. Subtotal abdominal hysterectomy was performed in both cases of ruptured uterus and amongst these two; one patient was subjected to internal iliac ligation.

Tasneem Ashraf in his study at Sandemam Civil Hospital, Quetta ${ }^{17}$ found that GMP's are at increased risk of PPH while Aslam $\mathrm{M}^{1}$ in his study at Lahore found no significant difference of PPH amongst GMP's and non-GMP's. Babinski et $a^{14}$ also found increased incidence of PPH amongst GMP, while Solo-Ojemo et al in their studies concluded that GMP's status is not a risk for $\mathrm{PPH}^{18}$.

Our study findings are supported by Karim SA et al who conducted a study on macrosomia at Agha Khan University Hospital, Karachi and found that GMP's status is a major risk for macrosomia ,. The increased incidence of macrosomia in GMPs is supported by studies throughout the world in both affluent and underdeveloped countries ${ }^{20,4,5}$.

In our study group, the perinatal mortality was $07 \%$ which is a significantly high number. The high mortality amongst the babies born to GMP mothers was not significant in a study conducted by Aslam M. ${ }^{1}$ Another study conducted by Babinski et al found no significant increase in perinatal mortality ${ }^{4}$.

There were 03 maternal deaths in our study. The maternal mortality rate was unacceptably high in different studies conducted by Njiru et $\mathrm{al}^{21}$ and Odukogbe et al. ${ }^{3}$

Aslam $\mathrm{M}$ in his study at KingEdwardMedicalCollege, Lahore found 07\% increase in maternal mortality amongst GMP's and labelled grand multiparity as risk to the mother ${ }^{1}$.

However, there are studies from developed world in which the maternal mortality is not different in GMP's from those of low parity group ${ }^{4,6}$.

Pregnancy in grand multiparae must be regarded as high risk pregnancy in terms of maternal and fetal complications and steps should be taken to reduce its prevalence. Improvement in socioeconomic conditions, providing adequate antenatal care and health care along with better acceptance of contraceptive methods can reduce the incidence of grand multiparity and its attendant complications. 


\section{CONCLUSION}

This study suggests that there is still high frequency of grand multiparity in our population. It is associated with frequent maternal and fetal complications and maternal and fetal mortality are high.

\section{REFERENCES}

1. Aslam M. Grand Multiparity. Specialist. Pak J Med Sci 1994; 10(4):317-21.

2. Anderson T, Bergstrom S, Hoobero U. Swedish Maternal Mortality in the $19^{\text {th }}$ century by different definitions, previous still births but not multiparity risk factor for maternal death. Acta Obstet Gynaecol Scand 2000; 79(8):679-86.

3. odukogbe AA, Adewole IF, Ojengbede OA, Olayemi $\mathrm{O}$, Fawole BO, Ahmed Y, et al. Grand multiparity trends and complications: a study in two hospitals settings University College Hospital, Lbadan, Oyo State, Nigeria. J Obstet \& Gynaecol 2001; 21(4):3617.

4. Babinski A, Kerenyi T, Torok O, Grazi V, Lapinsk RH, Berkowitz RL. Perinatal outcome in grand and great grand multiparity: effect of parity on obstetric risk factors. Am J Obstet Gynaecol 1999; 181(3):669-74.

5. Juntunen $\mathrm{K}$, Kirkinen $\mathrm{P}$, Kauppila A. The clinical outcome in pregnancies of grand grand multiparous women. Acta Obstet Gynaecol Scand 1997;76(8):775 $-9$

6. Bugg GJ, Atwal GS, Maresh M. Grand multiparae in modern setting. BJOG 2002; 109 (3); 249-53.

7. Ashraf T. Maternal Mortality: A four years Maternal Review JCPSP vol.6(3) 159-61

8. Afolabi A. F., Adeyemi A. S.: Open Journal of Obstetrics and Gynecology 2013; vol.3; 411-415.

9. Munim S, Rahber MH, Rizvi M, Mushtaq N. The effect of grand multiparity on pregnancy related complications; the Agha Khan University Hospital experience.JPMA 2000; 50 (2): 54-8.

10. Khaskheli M, Baloch S, Baloch AS. Obstetrical trauma to the genital tract following vaginal delivery. J Coll Physicians Surg Pak. 2012; 22(2):95-7.

11. Malik S, Naz F. Grand Multiparity: a continuing obstetric risk in Pakistan.J Surg Pak 2001; $6(2): 29-31$.

12. Mwambingu FT, AL Meshari AA, Akiel. A problem of grand multiparity in current obstetric practice. Int J Gynaecol Obstet 1988 Jun 26(3): 35: 5-9.

13. Afolabi AF, Adeyemi AS. Grand-multiparity: Is it still an obstetric risk? Open Journal of Obstetrics and Gynecology, 2013, 3, 411-415.

14. Halimi S. Association of placenta previa with multiparity and previous cesarean section. J Postgrad Med Inst Apr - Jun 2011; 25(2):139-42.
15. Maymon E, Ghezzi P, Shoham Vardio I, Hershkowitz R, Kartz M, Mazor M. Peripartum complications in grand multiparous women. Eur J Obstet Gynecol Reprod Biol 1998; 81(1):21-5.

16. Rizwan N, Parveen G, Abbasi RM. Frequency of grand multiparity and its fetomaternal outcome at Liaquat University Hospital, Hyderabad. Isra Med J Aug 2009; 1(2):49-53.

17. Ashraf T, Postpartum haemorrhage: An experience at sandeman CivilHospital, Quetta. JCPSP Oct 24, 1997 vol.8 (2): 68-71.

18. Selo Ojeme DO, Okonofua FE. Risk factors for primary postpartum haemorrhage. A case control study. Arch Gynecol Obstet 1997; 259(4):179-87.

19. Allahyar Jazayer. Macrosomia Clinical Presentation. Medscape. January 6, 2015.hptt//. emedicine. medscape. com/ article/262679-clinical Gul R. Maternal mortality: a preventable tragedy. J Med Sci Jul 2010; 18(3):140-2.

20. Njiru J, Biryabarema C, Kagaw M. Maternal outcomes among grand multiparous and multi parous women Muago Hospital Uganda. East African Medical Journal.2011 April; $\quad 88(4)$ 2011: 294.

\section{CORRESPONDENCE ADDRESS}

Dr. Saiqa Noor

Gynaecologist, DHQ Hospital Timergara

Cell No: 03009351818

Email Address: ikqazi61@yahoo.com 